NOTE

\title{
Purple sea urchins Strongylocentrotus purpuratus reduce grazing rates in response to risk cues from the spiny lobster Panulirus interruptus
}

\author{
Catherine M. Matassa*
}

Marine Science Center, Northeastern University, 430 Nahant Road, Nahant, Massachusetts 01908, USA

\begin{abstract}
The classical view of trophic cascades is that predators, by consuming herbivores, exert a positive indirect effect on plants. Although this form of trophic cascade has been demonstrated in a variety of terrestrial, aquatic, and marine systems, growing evidence suggests many trophic cascades are driven by anti-predator behaviors in prey. Despite abundant evidence of behavioral responses by sea urchins to predators, there has been little examination of how predation risk may influence urchin grazing rates. To determine if purple sea urchins Strongylocentrotus purpuratus graze less in the presence of predation risk, I monitored individual urchin grazing on the kelp Macrocystis pyrifera in the presence and absence of waterborne cues from damaged conspecifics and the predatory spiny lobster Panulirus interruptus. Sea urchin grazing rates were similar in the presence and absence of damaged conspecifics, but sea urchins exposed to lobster cues, regardless of lobster diet, reduced grazing rates by $44 \%$. Given that trophic cascades involving herbivorous sea urchins exert an important influence on primary production in kelp forests, these results suggest that predation risk may play an important but under-appreciated role in the dynamics of kelp forest food webs and primary production.
\end{abstract}

KEY WORDS: Non-consumptive effect · Trait-mediated indirect interactions · Trophic cascade · Kelp forest · Macrocystis pyrifera

Resale or republication not permitted without written consent of the publisher

\section{INTRODUCTION}

Our understanding of ecological communities has been greatly influenced by the idea that carnivores can indirectly control the abundance of plants via trophic cascades, wherein predators consume and thus limit the density of herbivores (Hairston et al. 1960, Paine 1980). The trophic cascade concept has driven a large body of experimental work documenting the top-down effects of predators on primary production and community structure in a variety of systems (for reviews see Pace et al. 1999, Shurin et al. 2002). The work of Estes \& Palmisano (1974) provides a classic example of a marine trophic cascade: sea otters enhance primary production in Northeast Pacific kelp forests by limiting populations of herbivorous sea urchins (see Peckarsky et al. 2008 for a recent perspective on this work). Echinivorous fish and crustaceans (Cowen 1983, Siddon \& Witman 2004) may be ecological analogues of sea otters in other kelp forests: in New Zealand, lobster predation on urchins controls the abundance of macrophytes (Shears \& Babcock 2002).

Trophic cascade research has traditionally focused on predators reducing herbivore density via consumption, but growing evidence suggests some predators can initiate trophic cascades without consuming prey (Trussell et al. 2002, 2003, 2006a, Werner \& Peacor 2003, Schmitz et al. 2004). Prey foraging activity often positively correlates with the probability of encountering a predator (Lima \& Dill 1990). Thus, prey must trade off the benefits of eating with the risk of being eaten in order to maximize individual fitness (Werner 
\& Anholt 1993). As a result, prey may reduce foraging activity when predators are detected (e.g. by visual or chemical cues), leading to positive indirect effects on prey resources similar to those produced when predators consume prey.

Several studies have documented behavioral changes in sea urchins in response to waterborne cues from predators or damaged conspecifics (Tegner \& Levin 1983, Mann et al. 1984, Hagen et al. 2002). For example, in the presence of rock crabs Cancer irroratus, green urchins Strongylocentrotus droebachiensis form aggregations as a defense against crab attack (Bernstein et al. 1981). Despite the strong role of urchins in trophic cascades and evidence for their sensitivity to predator cues, there has been little investigation into the importance of predation risk to urchinkelp interactions (but see Byrnes et al. 2006, Freeman 2006, McKay \& Heck 2008 for recent exceptions). The following study tests the hypothesis that purple urchins Strongylocentrotus purpuratus graze less on the kelp Macrocystis pyrifera in the presence of chemical cues released by the spiny lobster Panulirus interruptus or damaged conspecific urchins. The strength of non-consumptive predator effects ('risk effect size') was also estimated to compare the changes in consumer- resource interaction strength due to the various types of predation risk (Peacor \& Werner 2004, Trussell et al. 2006a, 2008).

\section{MATERIALS AND METHODS}

I conducted a series of 3 laboratory experiments to examine the individual grazing rates of purple sea urchins Strongylocentrotus purpuratus on the kelp Macrocystis pyrifera in the presence and absence of predator risk cues from the spiny lobster Panulirus interruptus and/or damaged conspecifics. P. interruptus, which feeds on echinoderms, mollusks, and crustaceans, is one of the dominant urchin predators in Southern California kelp forests (Tegner \& Dayton 1981), and exhibits a preference for $S$. purpuratus over its sympatric congener $S$. franciscanus (Tegner \& Levin 1983). Given the breadth of the spiny lobster diet, I also compared the effects of urchin-fed versus fish-fed lobsters on urchin grazing rates.

The experiments were conducted in the spring of 2005 at the Wrigley Marine Science Center (hereafter WMSC), Santa Catalina Island, California, USA. Twelve independent plexiglass aquaria $(60 \times 90 \times$ $30 \mathrm{~cm}$, width $\times$ length $\times$ height), each with its own drain and supply of flow-through seawater $\left(16\right.$ to $\left.18^{\circ} \mathrm{C}\right)$, were divided with acrylic egg crate $($ mesh size $=1 \mathrm{~cm})$ into a large 'risk cue' section and 4 small, adjacent compartments $(14 \times 10 \times 30 \mathrm{~cm})$ that housed individual urchins and kelp. For each experiment, 6 tanks were randomly assigned to the corresponding risk cue treatment, while the others served as cue-free controls. All tanks were drained and flushed with running seawater for at least $24 \mathrm{~h}$ between experiments and contained no sediments.

Urchins were collected in April 2005 from shallow $(<8 \mathrm{~m})$ rubble rock habitats within $4 \mathrm{~km}$ of WMSC. Urchins were stored in a single large aquarium tank and fed drift kelp, except during the starvation period ( 2 to $5 \mathrm{~d}$ ) before each experiment. For each experiment, 1 small $(<35 \mathrm{~mm}$ test diameter $)$ urchin, 2 medium (35 to $49 \mathrm{~mm}$ ) urchins, and 1 large (>49 mm) urchin were randomly selected, and each was placed in its own compartment within an aquarium tank. Organisms were never used twice and were returned to collection sites immediately after use in an experiment.

Each urchin was supplied an individual kelp ration: 10 rectangular pieces $(10 \times 5 \mathrm{~cm})$ of kelp blades collected from drift patches $2 \mathrm{~d}$ prior. Visible epifauna were removed from the kelp, and all cut pieces were stored in running seawater for at least $24 \mathrm{~h}$ before use. Rations were blotted dry with paper towels, weighed on a digital balance $( \pm 0.001 \mathrm{~g})$, and placed into assigned compartments. At the end of the experiment, all remaining kelp was removed and weighed as above. The amount of kelp consumed by a given urchin was calculated as the difference between the initial and final mass of that urchin's kelp ration. Kelp growth was very low during the experiment $(0.19 \pm$ $0.09 \mathrm{~cm}^{2} \mathrm{~d}^{-1}$ kelp piece ${ }^{-1}$, approximately $0.36 \% \mathrm{~d}^{-1}$ ). Given this negligible growth, the short duration of my experiments, and no evidence of poor tissue condition in kelp rations during the experiments, it is unlikely that inclusion of controls to adjust for autogenic effects would significantly alter my results or their interpretation.

The first experiment lasted $5 \mathrm{~d}$ and examined the effect of waterborne cues from urchin-fed spiny lobsters on the individual grazing rates of purple urchins that had been starved for the $2 \mathrm{~d}$ prior to initiation of the experiment. Six male and 6 female adult lobsters $(79.0 \pm 2.8 \mathrm{~mm}$ carapace length, mean $\pm \mathrm{SE})$, which are capable of consuming purple urchins of any size (Tegner \& Levin 1983), were collected along the coastline near WMSC. Of these, 3 males and 3 females were randomly selected for the first experiment. Each was placed in the risk cue section of 6 randomly assigned risk cue treatment tanks and fed a single urchin ( $~ 50 \mathrm{~mm}$ diameter) every evening while in the tank.

The second and third experiments each lasted $7 \mathrm{~d}$, and experimental urchins were starved for the $5 \mathrm{~d}$ prior to initiation of the experiment. The second experiment tested the effect of cues from damaged conspecifics 
and was designed to isolate the effect of lobsters from their urchin food in the first experiment. Damaged conspecific cues were created by placing an urchin ( $50 \mathrm{~mm}$ diameter) in the risk cue section of treatment tanks every night and puncturing its peristomial membrane with a $5 \mathrm{~mm}$ diameter metal rod, mimicking the method by which lobsters generally feed upon purple urchins (Tegner \& Levin 1983). Damaged urchins that remained alive after $8 \mathrm{~h}$ were cracked open and left in the tank to maximize risk cues. The third experiment was conducted to determine if cues from lobsters that did not consume urchins would have an effect similar to that of urchin-fed lobsters. The remaining 6 lobsters were individually placed in the 6 risk-cue tanks and fed a diet of frozen mackerel $\left(\sim 50 \mathrm{~g} \mathrm{~d}^{-1}\right)$ instead of urchins. Unconsumed mackerel was removed from the tanks after $3 \mathrm{~h}$.

For each experiment, the amount of kelp consumed by individual urchins was analyzed with nested analysis of covariance (ANCOVA), with the risk treatment as a fixed effect and urchin test diameter as a covariate. 'Tank' was considered a random effect nested within the risk treatment because the 4 urchins within each tank were not independent. The starvation period applied to urchins and the duration of the experiments varied, and thus the amount of kelp consumed by control urchins also varied among the 3 experiments (nested ANCOVA, $F_{2,15}=21.5, \mathrm{p}<$ 0.0001). Hence, I could not make direct comparisons of grazing rates for urchins exposed to the different risk treatments. Instead I obtained replicate estimates of 'risk effect size' for each experiment as 1 $\left(K_{\text {(risk) }} / K_{\text {(control) }}\right)$, where $K_{\text {(risk) }}$ is the average per capita amount of kelp consumed within each risk-treatment replicate and $K_{\text {(control) }}$ is the average per capita amount of kelp consumed by all control urchins in the corresponding experiment (see Peacor \& Werner 2004 and Trussell et al. 2006a for similar approaches). I analyzed replicate estimates of risk effect size $(n=6)$ with a 1-way analysis of variance (ANOVA) that considered risk type (urchin-fed lobsters, fish-fed lobsters, or damaged conspecifics) a fixed effect. The assumptions of all statistical tests were satisfied, and analyses were performed using JMP statistical software (SAS Institute).

\section{RESULTS}

Urchins Strongylocentrotus purpuratus consumed an average of $43 \%$ less Macrocysitis pyrifera kelp in the presence of risk cues from urchin-fed lobsters Panulirus interruptus $\left(F_{1,10}=5.970, p=0.035 ;\right.$ Fig. $\left.1 \mathrm{~A}\right)$. The presence of damaged conspecifics, however, had no effect on urchin grazing rates $\left(F_{1,10}=0.591, \mathrm{p}=0.46\right.$; Fig. 1B), suggesting that lobster cues alone were responsible for reduced urchin grazing rates in the first experiment. When exposed to fish-fed lobsters, grazing rates were reduced on average by $44 \%\left(F_{1,10}=\right.$ 14.341, $\mathrm{p}=0.004)$; however, this effect depended upon urchin size (lobster cues $\times$ urchin size interaction, $F_{1,34}=4.413, \mathrm{p}=0.008 ;$ Fig. $1 \mathrm{C}$ ). The grazing rates of urchins initially sorted into the small size class ( $<35 \mathrm{~mm}$ test diameter) were not affected by lobster cues, although medium and large urchins (>35 mm) reduced grazing rates by $57 \%$ in the presence of lobster cues (least-squares contrasts; $F_{1,32}=0.91, \mathrm{p}=0.3$ and $F_{1,32}=27.87, \mathrm{p}<0.0001$, respectively).
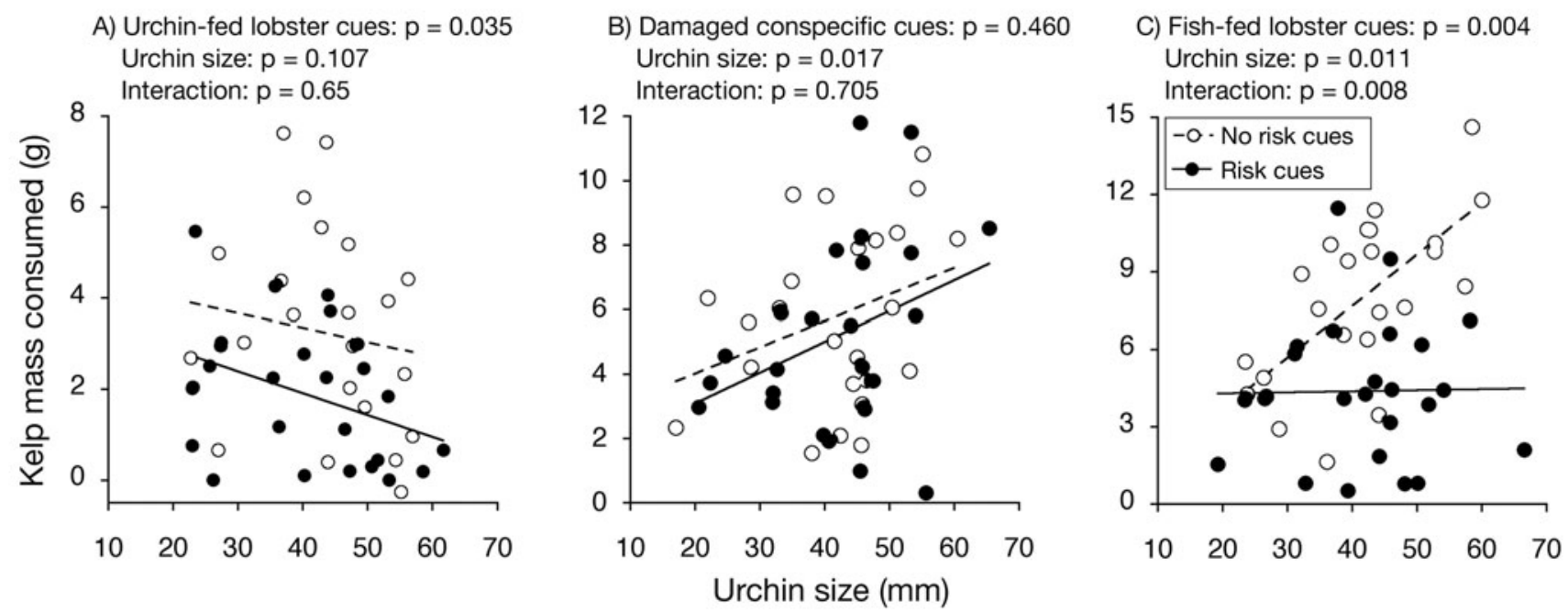

Fig. 1. Strongylocentrotus purpuratus. Mass (g) of kelp Macrocystis pyrifera consumed by S. purpuratus as a function of urchin size (test diameter, $\mathrm{mm}$ ) for urchins grazing in the presence (๑) or absence (O) of risk cues from (A) urchin-fed lobsters Panulirus interruptus, (B) damaged conspecifics, and (C) fish-fed lobsters 


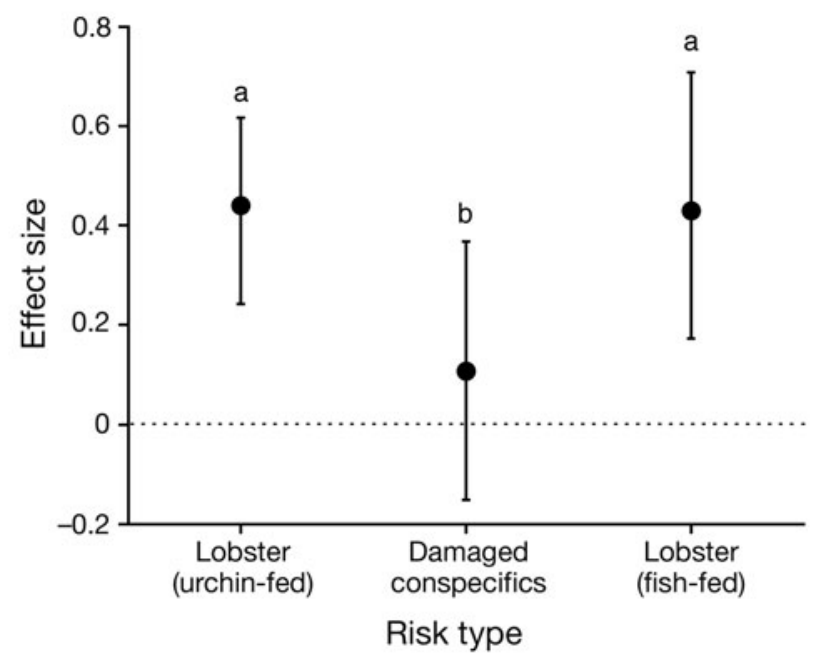

Fig. 2. Strongylocentrotus purpuratus. Mean size of risk effects (with $95 \%$ CI) from urchin-fed lobsters Panulirus interruptus, damaged conspecifics, and fish-fed lobsters. Different letters denote significant differences $(p<0.05)$ based on a post hoc Student's $t$-test. The size of the risk effect from damaged conspecifics is not significantly different from zero, indicated by the dotted line

Analysis of different risk cue effect sizes revealed that the effect of lobster cues did not depend on lobster diet (ANOVA, $F_{1,10}=0.007, p=0.9$; Fig. 2). Lobster cues had significantly stronger effects on urchin grazing than damaged conspecifics (least-squares contrast, $F_{1,15}=8.09, \mathrm{p}=0.01$ ). The risk effect size from damaged conspecifics was not significantly different from zero based on estimates of $95 \%$ confidence intervals (Fig. 2).

\section{DISCUSSION}

The presence of risk cues from predatory lobsters Panulirus interruptus, regardless of their diet, caused urchins Strongylocentrotus purpuratus to reduce grazing rates on average by between 43 and $44 \%$, while damaged conspecifics had no effect on urchin grazing rates. By reducing foraging or general activity when predators are present, prey may substantially reduce their risk of predation (Lima \& Dill 1990). An optimally foraging consumer must assess its environment before making foraging decisions in order to balance the benefits of foraging with the costs of predation risk (Werner \& Anholt 1993). Cues associated with a damaged but unconsumed conspecific may not indicate predation risk as reliably as those signaling actual presence of a predator (i.e. lobster). Previous work indicates that conspecific cues can induce prey defense, but predator risk cues are considerably more important (Trussell \& Nicklin 2002).
In the presence of fish-fed lobsters, medium to large urchins (>35 mm test diameter) reduced grazing by $57 \%$, while small urchins consumed kelp Macrocystis pyrifera regardless of predation risk. Theory predicts that prey may be more willing to accept predation risk during earlier developmental stages or when energetic reserves are low in order to avoid starvation (McNamara \& Houston 1987, Werner \& Anholt 1993, Schmitz et al. 2004). Smaller urchins $(<35 \mathrm{~mm})$ engage in more refuge behavior (Shears \& Babcock 2002), and consequently less foraging activity, potentially reducing energetic reserves. Thus, the decision to forage despite the presence of predators may reflect a critical need to meet energetic demands.

In the presence of urchin-fed lobsters, small, medium, and large urchins all reduced grazing rates. Cues from predators consuming conspecifics may elicit a stronger response in prey because they more reliably indicate prey-specific predation risk (Trussell \& Nicklin 2002). However, the different response of small urchins to urchin-fed versus fish-fed lobsters in my experiments may be confounded by the different starvation periods for urchins prior to each experiment ( 2 vs. 5 d, respectively). For example, non-starved urchins avoid chemically defended algae, while starved urchins graze indiscriminately (Cronin \& Hay 1996). The longer $5 \mathrm{~d}$ starvation period before the fish-fed lobster experiment may have had a greater impact on the energy reserves of small urchins as compared to large urchins, while such differences between size classes may not develop over a shorter (i.e. 2 d) starvation period. Hence, it appears that starvation thresholds may play an important role in dictating the responses of urchins to predation risk (McNamara \& Houston 1987).

Although my experiments cannot fully elucidate the effects of predator diet, it is clear that purple urchins reduced grazing rates in the presence of feeding lobsters. Risk cues from urchin-fed and fish-fed lobsters were equally effective at reducing grazing rates of urchins by 43 and $44 \%$, respectively, regardless of urchin size. The non-consumptive effect of predators on urchin- kelp interactions may contribute to trophic cascades and community dynamics in the kelp forests of Southern California by altering competitive interactions between kelp and other algae and between sea urchins and other herbivores. For example, the predatory starfish Pycnopodia helianthoides induces a strong escape response in Strongylocentrotus spp., which leads to localized reductions in urchin density and a spatial mosaic of patches with reduced herbivory, increased productivity, and increased species richness (Duggins 1983). Recent work suggests that non-consumptive predator effects can also alter ecosystem properties and functioning (Trussell et al. 2006b, 2008, Schmitz et al. 2008). 
Field experiments are necessary to determine how important lobster risk cues are to kelp forest dynamics, because these effects may depend on environmental factors like water flow and the availability of spatial and/or temporal refugia (Trussell et al. 2006a). Nevertheless, non-consumptive predator effects on prey and emergent indirect effects on basal resources (i.e. traitmediated indirect interactions) can be as strong as or stronger than consumptive predator effects and the density-mediated indirect effects they cause (Werner \& Peacor 2003, Schmitz et al. 2004, Trussell et al. 2006a, 2008). For example, the dogwhelk Nucella lapillus, an intermediate consumer on rocky shores, reduces its foraging rate on barnacles by $56 \%$ in the presence of risk cues from the green crab Carcinus maenas. The resulting positive indirect effect of predation risk on barnacles is 24 times stronger than that caused indirectly by consumptive predator effects on snail density (Trussell et al. 2006a). Many classic examples of density-based trophic cascades, including killer whalesea otter interactions and indirect effects on urchins and kelp (Estes et al. 1998), likely have a strong nonconsumptive component (Peckarsky et al. 2008). More experiments, especially in the field, are necessary to directly compare the strenth of consumptive and nonconsumptive predator effects in kelp forests and other marine systems. Future studies may reveal that the role of predation risk in structuring ecological communities is both strong and ubiquitous.

Acknowledgements. I thank G. C. Trussell for his tremendous support, as well as K. A. Miller, M. Wonham, S. Genovese, the WMSC staff, and EW XXI for guidance and assistance in the laboratory and in the field. Comments from 4 anonymous reviewers greatly improved this manuscript. This research, which partially fulfilled the requirements for the Professional Science Masters in Marine Biology degree, was supported by Northeastern University's Three Seas Program and by grants from the National Science Foundation to G. C. Trussell (OCE0648525, OCE-0727628). This is Contribution No. 265 of the Marine Science Center of Northeastern University.

\section{LITERATURE CITED}

Bernstein BB, Williams BE, Mann KH (1981) The role of behavioral responses to predators in modifying urchins' (Strongylocentrotus droebachiensis) destructive grazing and seasonal foraging patterns. Mar Biol 63:39-49

Byrnes J, Stachowicz JJ, Hultgren KM, Hughes AR, Olyarnik SV, Thornbert CS (2006) Predator diversity strengthens trophic cascades in kelp forests by modifying herbivore behavior. Ecol Lett 9:61-71

> Cowen RK (1983) The effects of sheephead (Semicossyphus pulcher) predation on red sea urchin (Strongylocentrotus franciscanus) populations: an experimental analysis. Oecologia 58:249-255

Cronin G, Hay ME (1996) Susceptibility to herbivores depends on recent history of both the plant and animal. Ecology 77:1531-1543
Duggins DO (1983) Starfish predation and the creation of mosaic patterns in a kelp-dominated community. Ecology 64:1610-1619

Estes JA, Palmisano JF (1974) Sea otters: their role in structuring nearshore communities. Science 185:1058-1060

Estes JA, Tinker MT, Williams TM, Doak DF (1998) Killer whale predation on sea otters linking oceanic and nearshore ecosystems. Science 282:473-476

- Freeman A (2006) Size-dependent trait-mediated indirect interactions among sea urchin herbivores. Behav Ecol $17: 182-187$

> Hagen N, Andersen A, Stabell O (2002) Alarm responses of the green sea urchin, Strongylocentrotus droebachiensis, induced by chemically labeled durophagous predators and simulated acts of predation. Mar Biol 140:365-374

$>$ Hairston NG, Smith FE, Slobodkin LB (1960) Community structure, population control, and competition. Am Nat 94:421-425

Lima SL, Dill LM (1990) Behavioural decisions made under the risk of predation: a review and prospectus. Can J Zool 68:619-640

Mann KH, Wright JLC, Welsford BE, Hatfield E (1984) Responses of the sea urchin Strongylocentrotus droebachiensis (OF Müller) to water-borne stimuli from potential predators and potential food algae. J Exp Mar Biol Ecol 79:233-244

> McKay KM, Heck KL Jr (2008) Presence of the Jonah crab Cancer borealis significantly reduces kelp consumption by the green sea urchin Strongylocentrotus droebachiensis. Mar Ecol Prog Ser 356:295-298

McNamara JM, Houston AI (1987) Starvation and predation as factors limiting population size. Ecology 68:1515-1519

Pace ML, Cole JJ, Carpenter SR, Kitchell JF (1999) Trophic cascades revealed in diverse ecosystems. Trends Ecol Evol 14:483-488

Paine RT (1980) Food webs: linkage, interaction strength and community infrastructure. J Ecol 49:666-685

Peacor SD, Werner EE (2004) How dependent are speciespair interaction strengths on other species in the food web? Ecology 85:2754-2763

> Peckarsky BL, Abrams PA, Bolnick DI, Dill LM and others (2008) Revisiting the classics: considering nonconsumptive effects in textbook examples of predator-prey interactions. Ecology 89:2416-2425

> Schmitz OJ, Krivan V, Ovadia O (2004) Trophic cascades: the primacy of trait-mediated indirect interactions. Ecol Lett 7:153-163

> Schmitz OJ, Grabowski JH, Peckarsky BL, Preisser EL, Trussell GC, Vonesh JR (2008) From individuals to ecosystem function: toward an integration of evolutionary and ecosystem ecology. Ecology 89:2436-2445

> Shears NT, Babcock RC (2002) Marine reserves demonstrate top-down control of community structure on temperate reefs. Oecologia 132:131-142

Siddon CE, Witman JD (2004) Behavioral indirect interactions: multiple predator effects and prey switching in the rocky subtidal. Ecology 85:2938-2945

Shurin JB, Borer ET, Seabloom EW, Anderson K and others (2002) A cross-ecosystem comparison of the strength of trophic cascades. Ecol Lett 5:785-791

Tegner MJ, Dayton PK (1981) Population structure, recruitment and mortality of two sea urchins (Strongylocentrotus franciscanus and $S$. purpuratus) in a kelp forest. Mar Ecol Prog Ser 5:255-268

Tegner MJ, Levin LA (1983) Spiny lobsters and sea urchins: analysis of a predator-prey interaction. J Exp Mar Biol Ecol 73:125-150 
Trussell GC, Nicklin MO (2002) Cue sensitivity, inducible defense, and trade-offs in a marine snail. Ecology 83: 1635-1647

Trussell GC, Ewanchuk PJ, Bertness MD (2002) Field evidence of trait-mediated indirect interactions in a rocky intertidal food web. Ecol Lett 5:241-245

$>$ Trussell GC, Ewanchuk PJ, Bertness MD (2003) Traitmediated effects in rocky intertidal food chains: predator risk cues alter prey feeding rates. Ecology 84:629-640

Trussell GC, Ewanchuk PJ, Matassa CM (2006a) Habitat effects on the relative importance of trait- and densitymediated indirect interactions. Ecol Lett 9:1245-1252

Editorial responsibility: Hans Heinrich Janssen, Oldendorf/Luhe, Germany
Trussell GC, Ewanchuk PJ, Matassa CM (2006b) The fear of being eaten reduces energy transfer in a simple food chain. Ecology 87:2979-2984

Trussell GC, Ewanchuk PJ, Matassa CM (2008) Resource identity modifies the influence of predation risk on ecosystem function. Ecology 89:2798-2807

Werner EE, Anholt BR (1993) Ecological consequences of the trade-off between growth and mortality rates mediated by foraging activity. Am Nat 142:242-272

Werner EE, Peacor SD (2003) A review of trait-mediated indirect interactions in ecological communities. Ecology 84:1083-1100

Submitted: April 29, 2009; Accepted: November 17, 2009

Proofs received from author(s): February 3, 2010 